\title{
STUDY ON SEASONAL VARIATIONS OF HEAT TOL- ERANCE IN YOUNG JAPANESE MALES AND EFFECTS OF PHYSICAL TRAINING THEREON
}

\author{
Seiki Hori, Akira InOuYe, * Heikichiro IHZuKa,* \\ and Toshio YAMADA** \\ Department of Physiology, Hyogo Medical College, Nishinomiya, Japan \\ *Department of Physiology, Kyoto University, School of Medicine, Kyoto, Japan \\ **Faculty of Industrial Arts, Kyoto Technical University, Kyoto, Japan
}

Summary 1. Physiological responses to heat and heat tolerance were examined in summer and winter on 39 male college students. After having been in the chamber for $30 \mathrm{~min}$, sweating was induced by immersing both legs up to the kness for $90 \mathrm{~min}$ a water bath of $42^{\circ} \mathrm{C}$ in a climatic chamber maintained at $30^{\circ} \mathrm{C}$ with $70 \%$ relative humidity. 2. Heat tolerance was assessed by heat strain cau ed by a certain heating condition. The heat strain was represented by a combination of relative increase in rectal temperature $(B)$ plus relative water loss $(A)$ and salt loss $(C)$. Indices $I$ and $S$ were defined, as reported previously, as $\left(A^{2}+B^{2}+C^{2}\right)^{1 / 2}$ and $B /\left(A^{2}+C^{2}\right)^{1 / 2}$, respectively, to assess the heat tolerance.

3. Sweating reaction in summer was characterized by a relatively smaller salt loss despite a greater water loss, while the rise in rectal temperature was less in summer than in winter.

4. The mean value of Index $I$ showed no significant seasonal differences, being 0.24 in both seasons. The mean values of Index $S$ in summer and winter were 0.81 and 1.42 , respectively, the difference being statistically significant.

5. The mean value of Index $I$ for the athlete group, which included college sportsmen, was significantly lower than that of the non-athlete group ( 0.21 and 0.27 , respectively, irrespective of the seasons), while no significant difference was found in Index $S$ between the two groups

6. Despite the lack of seasonal variation of Index $I$, the magnitude of individual $I$ showed a good correlation with heat tolerance as judged by the sweating type, in a classification system originally deve oped by Ohara.

7. Based on these results, applicability of the indices for the assessment of individual heat tolerance is discussed.

Received for publication January 7, 1974

堀 清記, 井上 章, 飯塚平吉郎, 山田敏男 
It has been known that physiological response to heat changes under the influence of climatic conditions. The onset of sweating has been shown to occur earlier and sweating becomes more profuse in summer than in winter when subjects are exposed to the same environmental conditions (KunO, 1934; AdolpH, 1946). Although many studies have been conducted concerning seasonal variation or climatic effect of physiological responses to heat exposure, such as chloride content in sweat or its relation to sweat rate (DILl et al., 1938; KUNO, 1934, 1956; OHARA, 1966), elaborate studies have not yet been made on heat tolerance which is a concept related to physiological strain due to many factors caused by heat. Reliable and practical methods of assessing heat tolerance have not really been established. Recently the authors proposed simple indices for the assessment of heat tolerance by estimating physiological strain which involves factors of relative increase in body temperature, water and salt losses (INOUYE, 1970; HoRI et al., 1974). Seasonal variations in physiological responses to heat were studied on young male students by means of the indices stated above. At the same time, the effects of physical training on heat tolerance were also examined by comparing the results obtained on college atheletes with those on non-athletes.

\section{MATERIALS AND METHODS}

Male Japanese students, aged 18-26, in Kyoto were selected as subjects. The subjects were clad only in shorts and sat resting in a chair in a climatic chamber at a temperature of $30^{\circ} \mathrm{C}$ with $70 \%$ relative humidity for $30 \mathrm{~min}$, after which they immersed both legs into a water bath of $42^{\circ} \mathrm{C}$ for $90 \mathrm{~min}$. The level of water was up to the kness. Experiments were carried out in the afternoon in February and August of 1970. The methods used for collecting local sweat samples and measurements of body weight loss as well as rectal temperature were the same as those reported in our previous work (HoRI et al., 1974).

The heat strain was estimated by a combination of relative increase in rectal temperature, water and salt losses. Two kinds of Indices, $I$ and $S$, were used for the assessment of heat tolerance or heat strain. The former represents the magnitude of heat strain as a whole and the latter represents the ratio of the magnitude of strain in heat content to that in water-electrolyte metabolism. Index $S$ was used to evaluate the degree of heat acclimatization (Hori et al., 1974). Assuming the critical values for rectal temperature and water and salt losses to be $40.6^{\circ} \mathrm{C}, 7 \%$ of body weight, and $0.75 \mathrm{~g}$ per $\mathrm{kg}$ of body weight, respectively (LEITHEAD and LIND, 1964), the following formulas were applied for calculation of the indices

$$
I=\left(A^{2}+B^{2}+C^{2}\right)^{1 / 2} \quad S=B /\left(A^{2}+C^{2}\right)^{1 / 2},
$$


where:

$$
\begin{aligned}
A & =\Delta W / 0.07 \mathrm{~W} \quad B=\Delta T /(40.6-T i) \\
C & =Q / 0.75 \mathrm{~W} \quad Q=0.058 \times \Delta W \times \bar{C} \\
W & =\text { Body weight before the experiment }(\mathrm{kg} \\
\Delta W & =\text { Weight loss at the end of the experiment }(\mathrm{kg}) \\
T i & =\text { Rectal temperature before the experiment }\left({ }^{\circ} \mathrm{C}\right) \\
\Delta T & =\text { Increase in rectal temperature at the end of the experiment }\left({ }^{\circ} \mathrm{C}\right) \\
Q & =\text { Salt loss by sweating during experiment }(\mathrm{g}) \\
\bar{C} & =\text { Mean Na concentration of local sweat samples }(\mathrm{mEq} / \mathrm{liter})
\end{aligned}
$$

A modified form of CRAIG's Index (1950), $I_{c}$, was calculated as follows:

$$
\begin{aligned}
I_{c} & =H / 100+\Delta T+\Delta W \times \bar{W} / W \\
H & =\text { Heart rate at the end of the experiment (beats } / \mathrm{min}) \\
\Delta T & =\text { Rise in rectal temperature at the end of experiment }\left({ }^{\circ} \mathrm{C}\right) \\
W & =\text { Initial body weight }(\mathrm{kg}) \\
\Delta W & =\text { Sweat production }(\mathrm{kg}) \\
\bar{W} & =\text { Mean values of initial body weight }(\mathrm{kg})
\end{aligned}
$$

Here it should be noted that the values of $T, W$, and $H$ at the end of heat exposure for $90 \mathrm{~min}$, instead of $60 \mathrm{~min}$, were used, as was the case in the original formula, and $\Delta W \times \bar{W} / W$ is used as the term for water loss.

Assessment of the sweating type of each individual was made by a modified form of Ohara's classification (HoRI et al., 1974), measuring the peak rate of local sweating $\left(V_{m}\right)$, the peak Na concentration $\left(c_{m}\right) Q^{\prime}=V_{m} \times c_{m}$ was plotted against $V_{m}$, and the three sweating types, $T$ (heat tolerant type), $N$ (normal type) and $U$ (heat intolerant type) were determined in reference to the mean value of both quantities and their probable deviations. However, it should be noted that, as the reference value of both population means and its probable deviation also included those reported by Ohara $(n=71$ in winter and $n=63$ in summer), no statistically significant difference was found between Ohara's subjects and ours (Hori et al., 1974).

In both series of our experiments, observations were made on 22 subjects, including 8 subjects who acted as volunteers during both seasons.

\section{RESULTS}

1. Seasonal difference in physiological responses to heat

As shown in Table 1, the mean values of body weight loss $(\Delta W)$ at the end of the experiment in summer were significantly larger than those in winter, whereas the mean values of the initial body weight $(W)$ were almost the same for both seasons. $\Delta W$ was larger the larger the body weight and was almost parallel with local sweat rate, except for a few cases, as in our previous report (Hori et al., 1974).

A great seasonal difference was observed in the mean $\mathrm{Na}$ concentration 
Table 1. Changes in body weight loss, rectal temperature and mean $\mathrm{Na}$ concentration in summer and in winter.

\begin{tabular}{lcc}
\hline & Summer & Winter \\
\hline$W$ & $60.71 \pm 5.41$ & $60.31 \pm 4.73$ \\
$\Delta W^{* *}$ & $0.74 \pm 0.14$ & $0.58 \pm 0.13$ \\
& $(0.42-0.98)$ & $(0.36-0.81)$ \\
$T$ & $37.3 \pm 0.28$ & $37.3 \pm 0.62$ \\
$T^{*}$ & $0.48 \pm 0.15$ & $0.62 \pm 0.15$ \\
$\bar{C}^{*}$ & $(0.15-0.74)$ & $(0.25-0.95)$ \\
& $44.8 \pm 19.1$ & $60.8 \pm 16.7$ \\
$H$ & $(16.7-83.9)$ & $(38.0-94.3)$ \\
$\Delta H$ & $71.9 \pm 6.6$ & $70.7 \pm 9.8$ \\
& $14.4 \pm 5.7$ & $16.3 \pm 4.0$ \\
& $5-27)$ & $(7-23)$ \\
\hline
\end{tabular}

Values are means \pm S.D. Those in parentheses indicate the range of variations.

$W$ and $\Delta W$ : Initial body weight and weight loss at the end of experiment $(\mathrm{kg})$

$T$ and $\Delta T$ : Initial rectual temperature and increase in rectal temperature at the end of experiment $\left({ }^{\circ} \mathrm{C}\right)$

$\bar{C}$ : Mean $\mathrm{Na}$ concentration in local sweat (mEq/liter)

$H$ and $\Delta H$ : Initial heart rate and increase in $H$ at the end of experiment (beat $/ \mathrm{min}$ )

* Difference was significant at $5 \%$ level

** Difference was significant at $0.1 \%$ level

Table 2. Seasonal variations of relative water loss $(A)$, relative rise in rectal temperature $(B)$, relative salt loss $(C)$ and the Indices $I, I_{c}$ and $S$.

\begin{tabular}{lcc}
\hline & Summer & Winter \\
\hline$A^{* *}$ & $0.176 \pm 0.038$ & $0.134 \pm 0.034$ \\
& $(0.089-0.253)$ & $(0.072-0.215)$ \\
$B^{* *}$ & $0.143 \pm 0.043$ & $0.193 \pm 0.046$ \\
& $(0.045-0.222)$ & $(0.096-0.317)$ \\
$C$ & $0.044 \pm 0.022$ & $0.045 \pm 0.018$ \\
& $(0.012-0.088)$ & $(0.017-1.082)$ \\
$I$ & $0.24 \pm 0.042$ & $0.24 \pm 0.045$ \\
& $(0.15-0.34)$ & $(0.17-0.34)$ \\
$S^{* *}$ & $0.81 \pm 0.30$ & $1.42 \pm 0.52$ \\
& $(0.19-1.56)$ & $(0.54-2.49)$ \\
$I_{c}$ & $2.08 \pm 0.27$ & $2.13 \pm 0.26$ \\
& $(1.60-2.63)$ & $(1.71-2.67)$
\end{tabular}

Values are means \pm S.D. Those in parentheses are the range of variations.

** Seasonal difference is significant at $0.1 \%$ level.

in local sweat. The average of the mean $\mathrm{Na}$ concentration in sweat collected at the chest and back was $45 \mathrm{mEq} /$ liter in summer and $61 \mathrm{mEq} /$ liter in winter; this finding is in agreement with the results reported by OHARA (1966). 
The initial level of rectal temperature was the same and any significant difference in the time development of the rise during heat loading was rarely observed between both seasons, however, the final level attained after 90 min was lower in summer than in winter, the difference being statistically significant.

The mean value of increase in heart rate at the end of the experiment was slightly lower in summer than in winter, however, the difference was not statistically significant.

Applying the relation (1), three terms-increase in rectal temperature $(B)$, the relative water loss $(A)$ and salt loss $(C)$-were computed. The population mean, standard deviation and range of these terms in summer as well as in winter are presented in Table 2 . The seasonal difference in $A$ and $B$ is statistically significant, and in summer, $A$ is greater and $B$, smaller. Sweating reaction in summer is characterized by a low $\mathrm{Na}$ concentration in sweat. Despite the higher sweating rate in summer, however, the $\mathrm{Na}$ loss term $C$ in summer shows no significant difference from that in winter.

\section{Seasonal effects on the indices}

The values of the Indices obtained are included in Table 2. Index $I$ as well as Craig's $I_{c}$ show no significant seasonal variation, while a high correlation between both indices ( $r=0.89$, significant at $1 \%$ level) was observed irrespective of the season (Fig. 1). On the other hand, the mean value of Index $S$ in summer was significantly lower than that in winter.

In view of the fact that earlier investigators often utilized increase in heart rate $(H)$ as a parameter for the assessment of heat tolerance, we examined whether or not there was a close correlation with our indices. However, both Indices $I$ and $S$ had hardly any correlation with $H$ or our parameter $D$ (see below). Next,

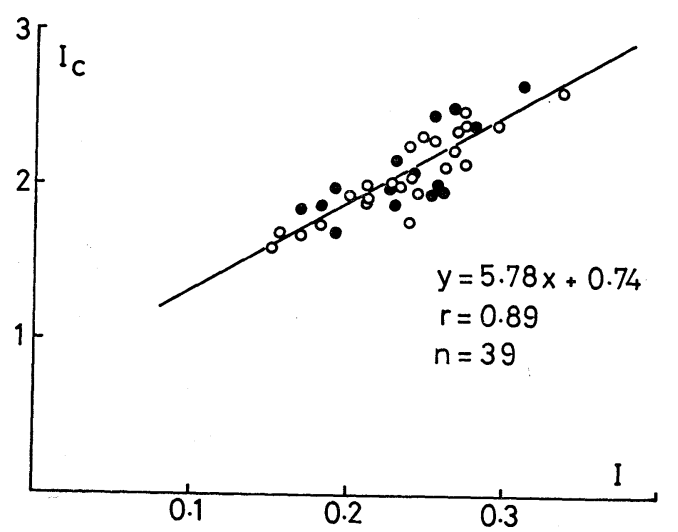

Fig. 1. Correlation between modified Craig's Index $I_{c}$ and Index $I$. Empty circles: summer experiment. Closed circles: winter experiment. 
we tried modified forms of the indices by introducing heart rate increase in the following way:

$$
I^{\prime}=\left(A^{2}+B^{2}+C^{2}+D^{2}\right)^{1 / 2} \quad I^{\prime \prime}=\left(A^{2}+B^{2}+D^{2}\right)^{1 / 2},
$$

where $D=\left(H-H_{i}\right) /\left(200-H_{i}\right)$, and $H_{i}$ and $H$ represent the heart rate at the beginning and at the end of the experiment, respectively. Both modified indices $\left(I^{\prime}\right.$ and $\left.I^{\prime \prime}\right)$ showed good linear correlation with Index $I(r=0.90$ and $0.93, P \leqq 0.01)$, which suggests that modifying Index $I$ by introducing a heart rate factor in such a form has no special advantage over the use of the original from the theoretical view point.

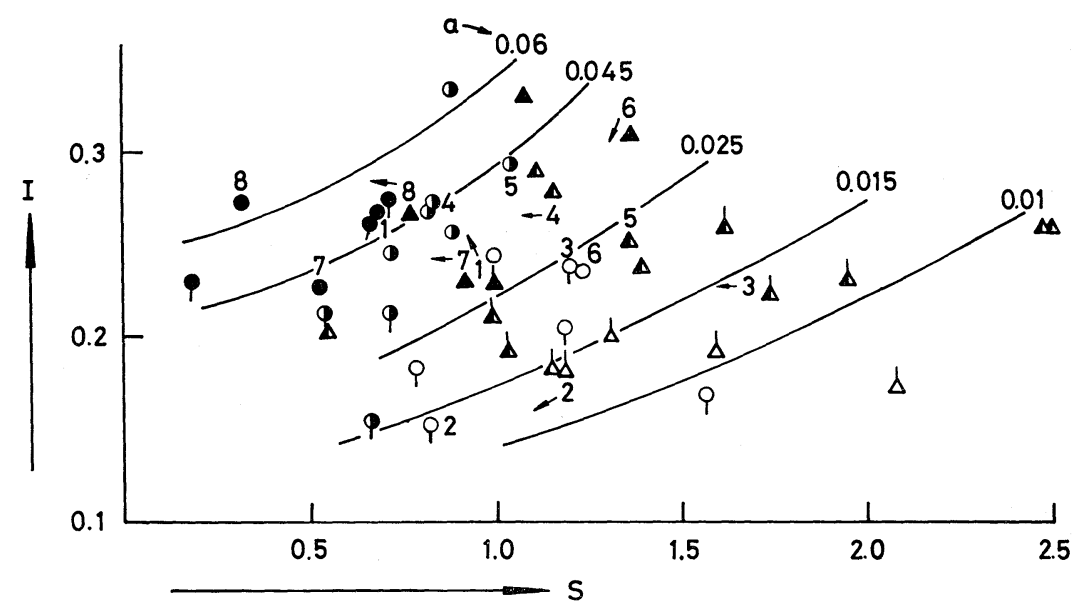

Fig. 2. Relationship between Indices $I$ and $S$. Triangles: winter experiment. Circles: summer experiment. Filled marks: represent sweating type U, half-filled, type $N$ and open ones, type T. Attached bar: represents members of the athlete group. Attached number: indicates the point observed on subjects Nos. 1-8. $\alpha$ : parameter of iso-sweating line defined in the previous paper (refer to Vol. 24 (3), 271 of this Journal) $\rightarrow$ : direction of seasonal change from summer to winter.

The relation between Index $I$ and Index $S$ is shown in Fig. 2. The result is quite similar to that reported previously. The observed points are widely scattered but those belonging to the heat tolerant type $\mathrm{T}$ show a tendency to localize in the lower right region in the figure, while those of type $U$, in the upper left. This finding is concordant with our expectation that the order of magnitude in $I$-value in the sweating types is $\mathrm{T}<\mathrm{N}<\mathrm{U}$. Indeed, the between-type differences of the sweating types $\mathrm{T}$ and $\mathrm{U}$ or $\mathrm{N}$ are statistically significant at a $5 \%$ level. The points obtained in the summer experiment are in the left half of the plot, thus demonstrating the fact that the $S$-value is lower in summer than in winter. 


\section{Difference between athletes and non-athletes}

In each series of the experiments, 11 of our 22 subjects were selected from students who had physical training after school as college athletes. Thus, the subject group was divided into two subgroups, the athelete group and the nonathlete group, and responses to standardized heat stress were compared.

The results of comparison are summarized in Table 3.

Table 3. Comparison of heat tolerance in athlete and non-athlete groups both in winter and summer.

\begin{tabular}{ccccc}
\hline & Season & $\begin{array}{c}\text { Athlete group } \\
(n=11)\end{array}$ & $\begin{array}{c}\text { Non-athlete } \\
\text { group }(n=11)\end{array}$ & $\begin{array}{c}P \text { ( } \\
\text { (in) }\end{array}$ \\
\hline$\Delta T$ & W & $0.55 \pm 0.092$ & $0.67 \pm 0.172$ & 5 \\
& S & $0.43 \pm 0.136$ & $0.55 \pm 0.137$ & 5 \\
$\bar{C}$ & W & $54.1 \pm 11.7$ & $67.7 \pm 16.0$ & 5 \\
& S & $35.9 \pm 14.1$ & $46.5 \pm 18.2$ & 5 \\
$\Delta H$ & W & $15.5 \pm 4.8$ & $17.2 \pm 4.0$ & - \\
& S & $11.9 \pm 5.2$ & $17.5 \pm 5.4$ & - \\
$A$ & W & $0.113 \pm 0.020$ & $0.157 \pm 0.032$ & 0.5 \\
& S & $0.132 \pm 0.039$ & $0.196 \pm 0.029$ & 0.1 \\
$B$ & W & $0.168 \pm 0.027$ & $0.210 \pm 0.054$ & 5 \\
& S & $0.122 \pm 0.038$ & $0.166 \pm 0.040$ & 0.5 \\
$C$ & W & $0.034 \pm 0.010$ & $0.058 \pm 0.016$ & - \\
& S & $0.031 \pm 0.017$ & $0.051 \pm 0.023$ & - \\
$D$ & W & $0.130 \pm 0.044$ & $0.154 \pm 0.043$ & - \\
& S & $0.090 \pm 0.038$ & $0.139 \pm 0.040$ & - \\
$I$ & W & $0.216 \pm 0.025$ & $0.273 \pm 0.041$ & 0.1 \\
& S & $0.209 \pm 0.040$ & $0.266 \pm 0.028$ & 0.5 \\
$I^{\prime}$ & W & $0.241 \pm 0.029$ & $0.307 \pm 0.041$ & 0.1 \\
& S & $0.230 \pm 0.044$ & $0.303 \pm 0.038$ & 0.1 \\
$S$ & W & $1.41 \pm 0.37$ & $1.37 \pm 0.50$ & \\
& S & $0.82 \pm 0.35$ & $0.81 \pm 0.30$ & \\
\hline
\end{tabular}

Values are means \pm S.D.

$P \lessgtr:$ level of significance in $\%$ for difference between the athlete group and nonathlete group

$\mathrm{W}$ and $\mathrm{S}$ : denote winter and summer, respectively.

(1) In both seasons, the relative sweat volume $(\Delta W / W$, which is proportional to A) as well as the mean $\mathrm{Na}$ concentration in sweat $\bar{C}$ are significantly lower in the athlete group than in the non-athlete group.

(2) There was no significant difference in relative salt loss by sweating between the two groups.

(3) The rise in body temperature of the athlete group was, irrespective of the seasons, significantly lower than that of the non-athlete group.

(4) No significant difference was observed in heart rate between the two groups. It follows that the average of Index $I$ for the athlete group is significantly 
lower than that of the non-athlete group, while the population mean of Index $S$ for both groups is almost identical, in summer and in winter. The average value of Index $I$ for each group showed no seasonal variation. Such findings are demonstrated in the $I$ vs $S$ plot (Fig. 2). It should be noted here that the heat tolerant type $\mathrm{T}$ is mainly occupied by the athlete group, irrespective of season ( 5 out of 6 cases in summer, and the same 5 cases in winter). In the athlete group, there was one exceptional case of $U$ type throughout both seasons, and another two cases in summer These three subjects showed higher $I$ values compared with the others in the athlete group. Such a fact appears to support the view, pointed out by Ohara's studies, that the sweating type reflects, though to a limited extent, individual ability to tolerate heat.

\section{Seasonal variations observed in the same subejcts}

A comparison of seasonal effects was done on a limited number of subjects, 8 out of 22 in each experiment, as shown in Fig. 2 by the numbers 1-8. In this figure, the $I$ value of No. 6 deviated from those of the other subjects. This may be due to some exper mental complications which are unavoidable in the field work. Without any apparent physical causes, subject No. 6, for example, lost $5 \mathrm{~kg}$ of body weight in the interval between summer and winter experiments, while the other subjects weighed about the same in both seasons. Even excluding such an exceptional case as No. 6, the reproducibility of Index $I$ was not so satisfactory (Fig. 3) and fluctuation of at most 0.03 existed. However, results outlined in Fig. 3 indicate that, to some degree, there is a linear correlation of Index $I$ in both seasons so that ranking according to the magnitude of $I$ in heat

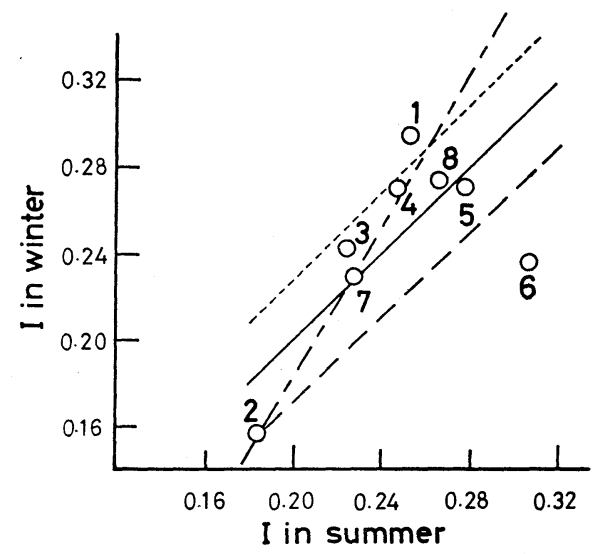

Fig. 3. Comparison of $I$ 's obtained on the same subjects in winter and in summer. The number of the point indicates the subject who corresponds to that in Fig. 2. It is shown that a rough correlation exists between the values in two seasons. The data are scattered around a regression line visually drawn through the points. Deviations from the regression line is approximately \pm 0.03 . 
tolerance has some practical merit

As pointed out by Ohara, the invariability of sweating type is fairly good, as seen in Fig. 2. Some exception was observed in two cases out of eight For example, No. 3, which was type $\mathrm{N}$ in winter, changed to type $\mathrm{T}$ in summer, and No. 6 from type $U$ in winter changed to type $T$ in summer. Thus, Index $I$ as well as the sweating type reflects, to a certain extent, the ability of each individual to tolerate heat.

\section{DISCUSSION}

It has been demonstrated that sweating occurs earlier and more profusely in summer but that the $\mathrm{Na}$ concentration is less than in other seasons (OHARA, 1966). KITTSTEINER, as early as in 1911, reported that the concentration of sweat $\mathrm{Cl}$ increased progressively as the rate of sweating increased. After repeated heat exposures, however, the salt concentration in sweat tends to decrease while the subjects sweat more readily and profusely (DILl et al., 1938, 1967; RoBINSON et al., 1943). Kuno (1956) concluded that the increase in sweat rate brought about by training in heat is attributable to an increase in the activity of the sweat glands, while increased excitability of the sweating center induced by frequent heat exposure causes the shortening of latency in sweating reflex. Decrease in the $\mathrm{Na}$ concentration in sweat as a result of training in heat may be due to increased functions of the adrenal cortex (CONN et al., 1946; ConN, 1949).

The results obtained in the present study are in good agreement. Since sweating increases considerably and $\mathrm{Na}$ concentration in the sweat decreases in summer, the heat-dissipating power of sweat may be greater in summer than in winter. Less increase in rectal temperature in summer may reflect such an increased evaporative heat loss caused by more profuse sweating with a lower $\mathrm{Na}$ concentration in the sweat and a prompt sweat reflex in summer. Indeed, it is well known that the shortening of the latent period for sweating reflex and higher sweat rate accompanying a lower body temperature are observed when unacclimatized subjects are exposed repeatedly to a hot environment (DILL et al., 1938; AdOLPH, 1946).

In the present study, subjects in the athlete group who undertood physical training almost every day showed sweating responses lower in rate and $\mathrm{Na}$ concentration and thus the subjects belong mostly to the sweating type $T$, while those in the non-athlete group belong mostly to type $\mathrm{N}$ or $\mathrm{U}$. At the same time, a rise in rectal temperature of the former group was lower than that of the latter. These results are not always concordant with the transitory adaptations due to repeated exposure to heat as stated above. Some of them may be explained partly by the physical characteristics of athletes and partly by "acclimatization" as has been observed in natives and settlers in the tropics.

As already noted by several investigators (BASS, 1963; BUSKIRK et al., 1965; 
EdHOLm et al., 1956; Houdas et al., 1972; STOLL, 1967), circulatory functions and subcutaneous fat play an important role in human thermal regulation. Generally, the cardiovascular system of athletes functions much better than that of non-athletes, while subcutaneous fat was reported to decrease in thickness under physical training (PASCALE et al., 1955; PARIzKOva, 1959). Indeed, mean skinfolds were found to be thinner in athletes than in non-athletes (NAGAMINE et al., 1966). Thus, these physical factors might result in a greater capacity of heat dissipation, with less sweating found in the athlete group. On the other hand, temperature regulatory responses with sweating the cardiovascular responses observed during physical training could be regarded as essentially the same as those induced by heat exposure (RoBINsON, 1963), whereas unacclimatized subjects more rapidly acclimatized to heat by hard muscular exercise under hot environments than by exposure to heat without exercise (BASs, 1963; RoBINSON et al., 1943). Kuno (1956) stated that both the sweating reflex and $\mathrm{Cl}$ concentration in sweat under a given heat stress are lower in tropical inhabitants than in Japanese, this acclimatization making for an increase of effectiveness of heat tolerance. Similar findings were also described by WyndHam et al. (1964) on Bantu.

When the strain in the body induced by heat exposure was assessed in terms of relative rise in rectal temperature, water and salt loss, the magnitude of strain in water metabolism $(A)$ was greater in summer than in winter, and that of salt metabolism $(C)$ was hardly affected in both seasons, whereas the magnitude of strain in thermal regulation $(B)$ was greater in winter than in summer. Such changes in the three parameters are in good agreement with the above-stated seasonal variations of physiological responses. Since the seasonal changes in $A$ and $B$ are in opposite directions, it is quite natural that the heat tolerance in summer assessed by our Index $I$ showed hardly any significant difference from that in winter despite a drastic change in the pattern of strain, which is well reflected in the significant difference in Index $S$.

Such a finding raises the question of whether or not Index $I$ is actually useful for assessment of individual heat tolerance. At the present stage of investigation, we do not have an a priori criteria for "heat tolerance". The problem is one of definition.

Sometimes greater ability to perform a task under the same heat stress is applied as an indicator of higher tolerance to heat (e.g., RoBINSON et al., 1943; WYNDHAM and WiLliams, 1967), and at other times such adaptive changes in physiological responses to heat as observed on natives of tropics are applied (KUNO, 1956). Ohara's sweating type method can be regarded as an approach developed along Kuno's line of investigation. Our Index $I$ is introduced, however, as a measure for physiological strain in heat balance as a whole, as the result of a heat stress. Such an application of the concepts in engineering of stress and strain to heat balance in humans has already been attempted by some investigators (e.g., Robinson et al., 1945; Craig, 1950; Belding and Hatch, 1955). 
The present study demonstrates that, for a Japanese, the magnitude of physiological strain under a given heat stress estimated as Index $I$ is not always less in summer than in winter. From such a viewpoint, a Japanese may not necessarily be able to tolerate heat more easily in summer than in winter. In Japan, summers are hot and humid, but not as lengthy as in the torrid zone, while winters are cold. The effect on so-called heat tolerance of hot summers in Japan would be, therefore, quite different from that of all-year-round hot climate in the torrid zone, where individuals gain and maintain a high tolerance to heat with relative ease (KUNO, 1956).

On the other hand, as demonstrated above, a significant difference in the magnitude of Index $I$ was observed between athletes and non-athletes (Table 2), while there was found a close correlation to heat tolerance as estimated by the sweating type method (Fig. 2). Moreover, reproducibility of the value of Index $I$ for each individual was to some extent demonstrated (Fig. 3). It may thus be concluded that Index $I$ reasonably reflects the magnitude of heat tolerance; hence, the tolerance of heat by a young male Japanese may be supposed to remain almost the same year-round, or it may indicate the individual's characteristic of heat tolerance which is inherent in his thermal adaptability.

As already noted by many investigators, the pattern of physiological responses under heat is quite different in hot and cold seasons. Such adaptive changes in the pattern of component strains are well mirrored on changes in Index $S$ (Table 2 and Fig. 2). As described in relation to the Equation $I=a\left(1+S^{2}\right)^{1 / 2}$ (refer to Hori et al., 1974), the lower the value of Index $S$ for a given $I$, the more effective the evaporative heat loss. This fact is concordant with the effects of adaptation to heat. Hence, it may be reasonable that Index $S$ can be utilized as an indicator for such adaptive changes.

Thus the results of the present study indicate that the concept we have developed with regard to indices for the assessment of heat tolerance provide a reasonable basis for comparing the heat tolerance of an individual or of one population with that of another.

As shown in Fig. 1, a close correlation was found between Craig's Index and our Index $I$. The modified Index $I^{\prime \prime}$ also showed a good linear correlation with the original Index $I$. From a practical point of view, therefore, it can be said that these are useful as a substitute for our Index $I$ in field studies. Omitting the term $C$ in these indices is practical for field work, and eliminates collecting sweat samples, measuring the volume and determining the $\mathrm{Na}$ content therein.

\section{REFERENCES}

Adolph, E. F. (1946) The initiation of sweating in response to heat. Am. J. Physiol., 145: $710-715$.

BAss, D. E. (1963) Thermoregulatory and circulatory adjustments during acclimation to heatin man. In Temperature, its Measurement and Control. Vol. 3. Reinhold, New York: 229-305. 
Belding, H. S. and НATcH, T. F. (1955) Index for evaluating heat stress in terms of resulting heat strains. Heat Pip. Air Cond., 27: 129-136.

Buskirk, E. R., Lundegren, H., and Magnusson, L. (1965) Heat acclimatization patterns in obese and lean individuals. Ann. N. Y. Acad. Sci., 131: 637-653.

CraIG, F. N. (1950) Ventilation requirements of an impermeable protective suit: the influence of temperature, humidity and flow of ventilating air on physiological strain. Med. Div. Res. No. 5, Corp. Army Chem. Center, Maryland.

ConN, J. W. (1949) Electrolyte composition of sweat; clinical implication as index of adrenal cortical function. Arch. Int. Med., 83: 416-428.

Conn, J. W., Johnson, M. W., and Louis, L. H. (1946) Acclimatization to humid heat; A function of adrenal cortical activity, J. Clin. Invest., 25: 912-913.

Dill, D. B., Hall, F. G., and Edwards, H. T. (1938) Changes in composition of sweat during acclimation to heat. Am. J. Physiol., 123: 412-419.

Dill, D. B., Horvath, S. M., Beaumont, W. V., Gehlsen, G., and Burrus, K. (1967) Sweat electrolytes in desert walks. J. Appl. Physiol., 23: 746-751.

Edholm, O. G., Fox, R. H., and MacPherson, R. K. (1956) The effect of body heating on the circulation in skin and muscle. J. Physiol. (Lond.), 134: 612-619.

Hori, S., Inouye, A., and Ihzuka, H. (1974) Indices and sweating patterns for the assessment of heat tolerance. Jap. J. Physiol., 24: 263-275.

Houdas, Y., Colin, J., Tembal, J., Boutelier, C., and Guieu, J. (1972) Skin temperatures in warm environments and the control of sweat evaporation. J. Appl. Physiol., 33: 99-104.

InOUYE, A. (1970) Analysis of heat tolerance. Proc. 11th Meeting on "Analysis of Tolerance to Heat and Cold and Its Methodology", p. 7-8 (in Japanese).

Kittsteiner, C. (1911) Sekretion, Kochsaltgehalt und Reaktion des Schweisses. Arch. Hyg. Berl., 73: 275-306.

Kuno, Y. (1934) The Physiology of Human Perspiration. Churchill, London.

Kuno, Y. (1956) Human Perspiration. Charles C. Thomas, Springfield.

Leithead, C. S. and Lind, A. R. (1964) Heat Stress and Heat Disorders. Davis, Philadelphia.

Nagamine, S., Kuga, T., Yamakawa, K., Ohima, S., Suzuki, H., and Suzuki, S. (1966) The comparison of body composition between athletes and non-athletes. Jap. J. Nutr., 24: 3-8 (in Japanese).

OHARA, K. (1966) Chloride concentration in sweat; Its individual, regional, seasonal and some other variations and interrelations between them. Jap. J. Physiol., 16: 274-290.

Pascale, L. R., Frankel, T., Grossman, M. I., Freeman, S., Falier, I. L., and Bond, E. E. (1955) Report of changes in body composition of soldiers during paratrooper training. Army Med. Nutrition Lab., Denver Col., Rep. No. 156, 1-14.

PARIzkova, J. (1959) The development of subcutaneous fat in adolescents and the effect of physical training and sport. Physiol. Bohem., 8: 112-113.

Robinson, S. (1963) Temperature regulation in exercise. Pediatrics, 32: 691-702.

Robinson, S., Turrell, E.S., and Gerking, S. D. (1945) Physiologically equivalent condition of air temperature and humidity. Am. J. Physiol., 143: 21-32.

Robinson, S., Turrell, E. S., and Horvath, S. M. (1943) Rapid acclimatization to work in hot climates. Am. J. Physiol., 140: 168-176.

Stoll, A. M. (1967) Heat transfer in Biotechnology. Adv. Heat Transfer, 4: 65-141.

Wyndham, C. H., Strydom, N. B., Morrison, J. F., Williams, C. G., Bredell, G. A. G., von Rahden, M. J. E., Holdworth, L. D., van Graan, C. H., van Rensburg, A. J., and Munro, A. (1964) Heat reactions of Caucasians and Bantu in Africa. J. Appl. Physiol., 19: 598-606.

Wyndham, C. H. and Williams, C. G. (1967) South African test II. Heat stress limits for a moderate rate of work for U.S. students and Bantu. In Comparative Methodology for Heat Tolerance Testing, A Cooperative International Study. U.S. Dept. of NEW Public Health Service, Natl. Center for Urban and Indust. Health, Cincinnati, Ohio, 38-64. 